RFP-2938

July 2, 1980
RFP-2938

July 2, 1980

\title{
TRANSDUCER CHARACTERIZATION
}

\author{
B. T. Cross \\ J. M. Eoff \\ L. J. Schuetz \\ $K$. R. Cunningham
}

Research and Engineering

TRANSDUCER CENTER

\section{Rockwell International \\ Energy Systems Group \\ Rocky Flats Plant \\ P.O. Box 464 \\ Golden, Colorado 80401}

U. S. DEPARTMENT OF ENERGY

CONTRACT DE-AC04-76DPO3533 


\section{DISCLAIMER}

This report was prepared as an account of work sponsored by an agency of the United States Government. Neither the United States Government nor any agency Thereof, nor any of their employees, makes any warranty, express or implied, or assumes any legal liability or responsibility for the accuracy, completeness, or usefulness of any information, apparatus, product, or process disclosed, or represents that its use would not infringe privately owned rights. Reference herein to any specific commercial product, process, or service by trade name, trademark, manufacturer, or otherwise does not necessarily constitute or imply its endorsement, recommendation, or favoring by the United States Government or any agency thereof. The views and opinions of authors expressed herein do not necessarily state or reflect those of the United States Government or any agency thereof. 


\section{DISCLAIMER}

Portions of this document may be illegible in electronic image products. Images are produced from the best available original document. 
This report was prepared as an account of work sponsored by an agency of the United States Government. Neither the United States Government nor any agency thereof, nor any of their employees, makes any warranty, express or implied, or assumes any legal liability or responsibility for the accuracy, completeness, or usefulness of any information, apparatus, product, or process disclosed, or represents that its use would not infringe privately owned rights. Reference herein to any specific commercial product, process, or service by trade name, trademark, manufacturer, os otherwise, does not necessarily constitute or imply its endorsement, recommendation, or favoring by the United States Government or any agency thereof. The views and opinions of authors expressed herein do not necessarily state or reflect those of the United States Government or any agency thereof.

Printed in the United States of America Available from the

National Technical Information Service

U.S. Department of Commerce

Springfield, Virginia 22161

Page Range

Domestic Price*

001-025

ก26-050

051-075

$\$ 5.00$

6.00

076-100

7.00

8.00

*All microfiche are priced at $\$ 3.50$

Prices Subject to Change Without Notice 
Printed

July 2, 1980
RFP-2938

UC-38 ENGINEERING AND EQUIPMENT

TIC- 4500 (Rev. 67)

\section{TRANSDUCER CHARACTERIZATION}

\author{
B. T. Cross
}

J. M. Eoff

L. J. Schuetz

K. R. Cunningham

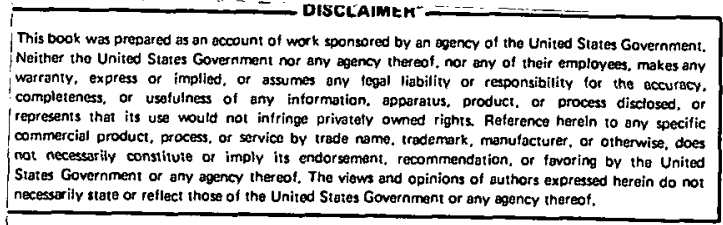

SUBJECT DESCRIPTORS

Nondestructive Testing

Transducers
ROCKWELL INTERNATIONAL ENERGY SYSTEMS GROUP ROCKY FLATS PLANT
P.O. BOX 464
GOLDEN, COLORADO 80401

\footnotetext{
Prepared under Contract DE-AC04-76DPO3533 for the Albuquerque Operations Office U.S. Department of Energy
} 
RFP-2938 


\section{CONTENTS}

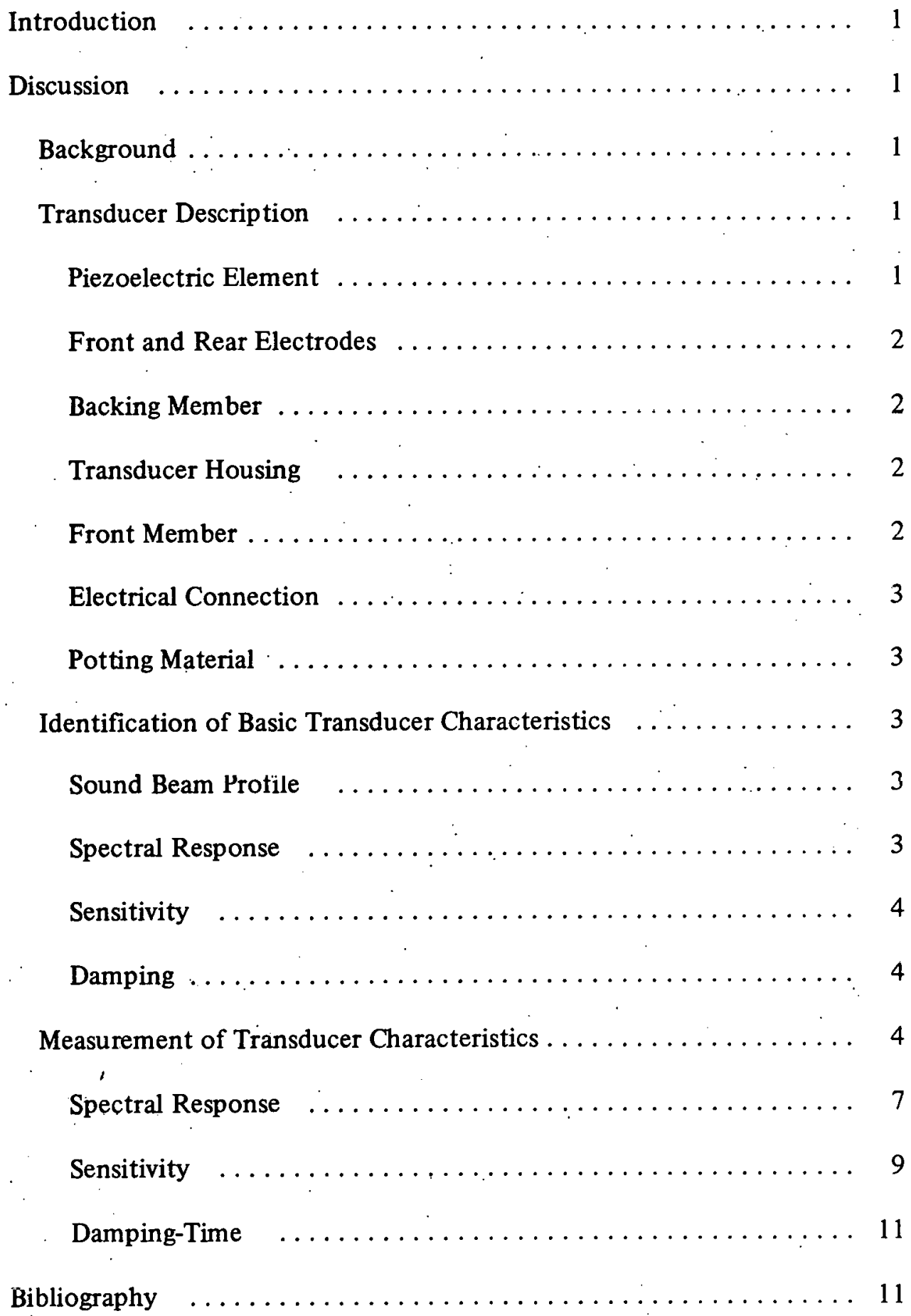


RFP-2938 


\title{
TRANSDUCER CHARACTERIZATION
}

\author{
B. T. Cross, J. M. Eoff, L. J. Schuetz, \\ and $K . R$. Cunningham
}

\section{INTRODUCTION}

This report has been prepared specifically for ultrasonic transducer users within the Nondestructive Testing Evaluation (NDE) community of the weapons complex. The purpose of the report is twofold: (a) To establish an initial set of uniform procedures for measuring and recording transducer performance data, and (b) To establish a common foundation on which more comprehensive transducer performance evaluations may be added as future transducer performance criteria expands.

The information contained within this report has been gathered from many sources and is presented in a form suitable to the complex's needs.

An important consideration regarding the recommended procedures is the cost of implementation. There are two distinct needs for transducer performance characterization in the complex. Production oriented users need a quick, reliable means to check a transducer to aseertain its suitability for continued service. Development groups and the Transducer Center need a comprehensive characterization means to collect adequate data to evaluate theoretical concepts or to build exact replacement transducers. The instrumentation, equipment, and procedures recommended for monitoring production transducers are utilitarian and provide only that information needed to determine transducer condition.

This report has been prepared in two parts: (a) a brief discussion of transducer parameters and the problems with measuring them, and (b) recommended procedures for measuring transducer performance with special precautionary notes regarding critical aspects of each measurement.

\section{DISCUSSION}

\section{Background}

In current practice, there are no practical NBS (National Bureau of Standards) traceable performance measurements suitable for measuring NDE transducers outside of specially equipped laboratories. Therefore, transducer performance measurements must be qualified by documenting all the test variables. This is the first problem. To qualify measurements by documentation, it is necessary to first guarantee that everyone making those measurements identified the parameters by the same terminology.

The following text is an initial step in establishing a common technology base and terminology for ultrasonic transducers within the complex.

\section{Transducer Description}

An ultrasonic transducer is an electromechanical device utilizing a piezoelectric element to convert electrical energy to acoustical energy and vice versa. Specifically, the transducer consists of several parts, each making a particular contribution to its performance. Eách part shown in Figure 1 is identified and discussed in the following paragraphs.

\section{Piezoelectric Element}

Piezoelectricity is characteristic of many materials including certain crystals, ceramic compounds, and polymers. Piezoelectric materials are characterized by many material properties; however, those properties commonly used for NDE transducers are

(a) g constant - an indicator of performance in converting mechanical pressure to electrical charge - commonly called the receiving constant.

(b) d constant - an indicator of performance in converting electrical energy to mechanical force - commonly called the transmission constant.

(c) $\mathrm{e}_{\mathrm{r}}$, relative dielectric - indicates the electrical capacitive nature of the device. 


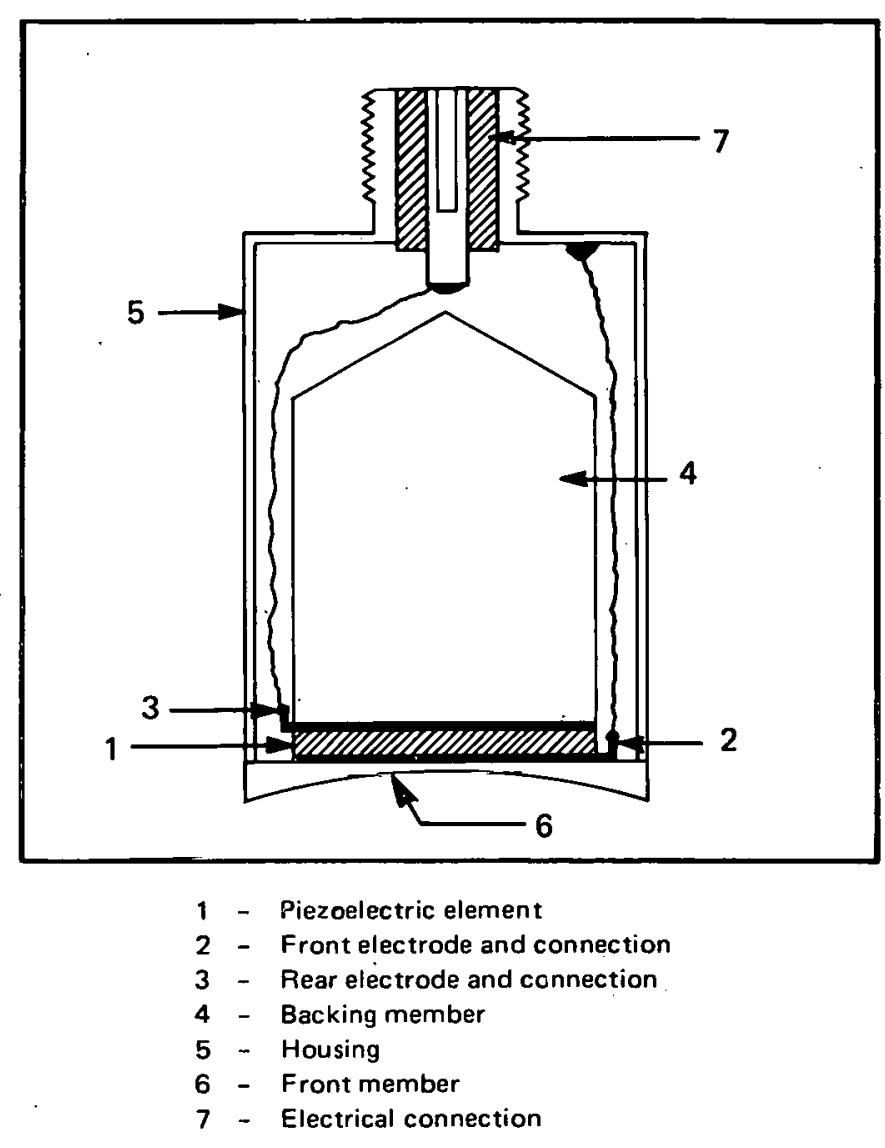

FIGURE 1. Basic Transducer Components

(d) $\mathrm{N}$, frequency constant - indicates the relation between material thickness and resonant frequency - also $\mathrm{N}$ is equal to $1 / 2$ the acoustical velocity of the material.

(e) $\rho$, material density - material density.

(f) K, mechanical coupling coefficient - indicates the ability to convert energy from one form to another.

(g) $\quad \underline{\mathrm{K}^{2}}=($ stored mechanical energy $) \div($ total stored energy).

Whatever the nature of the element, it is always the component in a transducer that converts energy. Historically, piezoelectric elements have been called "crystals" even though the material may be ceramic or polymeric.
Front and Rear Electrodes

Electrical conductance between two opposing element surfaces is required to make a piezoelectric element operational. This conductance is achieved placing electrodes on the appropriate surfaces by vapor deposition of a conductive film, adhesively bonding of metallic foil, or mounting the element on a conductive backing member. Common practice is to connect the rear electrode to the center pin of the connector (No. 7, Figure 1) and the front electrode to the housing (No. 5, Figure 1) which makes the front electrode and housing the ground or low potential connection.

Backing Member

The backing member has several important functions in the operation of a transducer. It is the structural member on which the fragile piezoelectric element is supported. The acoustic energy generated by a piezoelectric element is transmitted in both the forward and reverse directions. The forward traveling wave becomes the sound beam used for NDE. The rearward traveling energy must be absorbed to prevent spurious reflection that might be mistaken for NDE test data. Thus, the backing is also an. acoustical energy absorber. Another backing member function is in the control of transducer spectral performance. Proper selection of backing material can significantly alter the useable frequency range (or bandwidth) of a transducer.

\section{Transducer Housing}

Transducer elements are excited by high voltage pulses. Piezoelectric elements are subject to both mechanical and environmental damage. The housing provides protection for both the fragile element and the NDE operator. Special transducer housings are often used to provide custom means for mechanically connecting the transducer to a test scanner for a unique inspection.

\section{Front Member}

Front members are usually faces placed on the front end of a transducer element for any of several 
reasons. One common reason is to protect the delicate element from a detrimental environment. A front face made of special abrasion-resistant material may be used to protect the piezoelectric element from undue wear. The major use of front faces, however, is in the form of an acoustical lens for shaping or focusing the sound beam.

\section{Electrical Connection (No. 7, Figure 1)}

All transducers require electrical connection to the ultrasonic testing instrument. The most common means of connection is by coaxial cable. Generally, transducer connectors match standard commercial coaxial cable connectors-UHF, BNC, and micro-dot being the most popular. Cable connection choice is determined by type of transducer use and type of support instrumentation.

\section{$\underline{\text { Potting Material }}$}

The empty volume in an assembled transducer is often filled with a potting material to both seal the components and rigidly secure the parts from movement.

\section{Identification of Basic Transducer Characteristics}

A transducer has several performance characteristics that are unique to its design, shape, size, and element material. These basic characteristics are sound beam shape or profile, power spectrum response, sensitivity, and electrical impedance. The actual performance of any given element can be significantly altered from its basic character by adding a focusing lens, a special electrode configuration, or other such design features. However, once a transducer has been fabricated, its characteristics are unique to itself or any identical transducer. These unique characteristics provide a practical means for fabricating identical replacement transducers and for periodically checking transducer performance for degradation. The following scctions present a brief description and discussion of these hasic transducer characteristics.

\section{Sound Beam Profile}

When electrically excited, a piezoelectric element becomes a radiant source of acoustical energy. The shape and direction of the acoustic energy path is called the sound beam profile. A mathematical description of this path is called the directivity function. By measuring the axial and cross-sectional pressure distribution within the transmitted acoustical field, we can construct a map of the sound field, thereby identifying the uniquely characteristic sound beam profile of the transducer. It is important to note, however, that any point in this unique sound beam profile will remain fixed so long as there are no changes in method of excitation, method of measuring, or in the transducer.

\section{Spectral Response}

A transducer element is a frequency-sensitive device in both an active and a passive sense. The active aspect of the element occurs when it is electrically excited and attempts to vibrate at the element's simple mechanical resonant frequency. Also, mechanical excitation causes the element to attempt vibration at simple resonance. The emphasis on "attempted vibration" is an intentional effort to make the reader aware that a transducer's spectral response may and often does vary significantly from the free spectral response of the element. A piezoelectric element will try to follow the driving function of an external energy applied to its body. This is true whether that energy be electrical or mechanical. Therefore, the total spectral response of a transducer is a combination of its response to the driving force and its element's natural resonant response. This point is very important in understanding transducer performance and why a transducer's real response may vary considerably with its theoretical response. The thickness of an element determines its free or unclamped resonant frequency; however, the operating frequency of a transducer is altered by many of its electrical and mechanical design features. Sandwich type construction can significantly shift the resonant frequency of an operating transducer.

Piezoelectric elements are often classified into two catagories according to the ease with which the 
element can be made to operate at some frequency other than its natural resonance. "Dominant" elements are difficult to force into non-resonant operation. "Non-dominant" elements, such as lithium sulphate or polymeric materials, are easily forced to operate over a wide range of frequencies. Ceramic elements are typical of the dominant class. Dominant classification does not mean such elements cannot be made to operate over a wide band but merely such off-frequency operation is more difficult to achieve.

Spectral response is a unique, invariant characteristic, providing no measurement or transducer change occurs. The spectrum measurement gives a measure of acoustical power versus acoustical frequency for the transmitted sound wave at the point where it is sampled. The significance of the "dominant"/"nondominant" classification is manifested in this measurement by the susceptibility of spectrum changes in nondominant transducers due to minor pulser variations.

\section{Sensitivity}

Sensitivity is a nebulous term when used for transducer characterization unless rigidly defined by both method of measurement and the exact quantity being measured. The most common sensitivity measurement is called "loop-gain." While this parameter name is somewhat misleading, it has gained fairly common usage. The "loop-gain" parameter is the ratio of the received reflected signal amplitude from a known target and the pulse voltage applied to the transducer. The measurement is made in pulse-echo operation.

\section{$\underline{\text { Damping }}$}

Damping is truly an integral part of the spectral response of a transducer; however, this term is commonly used to indicate the resolution capability of a transducer. Damping as used for NDE is a measure of the number of cycles required for the transducer to stop vibrating after cessation of an externally applied excitation. Because this term can be grossly misleading, two actions have been taken in this report to alleviate the subjectivity in the use of the term "Damping." The frequency range of operation or bandwidth of the transducer shall be determined from its spectral measurement and shall be called "Bandwidth." The time interval required for a transducer to reach quiescense after an externally applied mechanical excitation will be called "Damping-Time" or "DT" and be given in units of nanoseconds. The exponential curve of the decaying sinusoidal transducer response decreases by an $e^{-k t}$ term. The exponent " $k$ " will be called the "Damping Factor" or "DF."

\section{Measurement of Transducer Charasteristics}

Specific transducer characteristics have been identified. Potential sources of variability that must be considered when making transducer measurements have been noted. Now we address specific transducer parameter measurements and the unique problems and precautions related to each. Each transducer measurement is discussed in two parts; first, the concept of measurement and second, a recommended procedure.

Sound Beam Profile Concept of Measurement: Making a sound beam profile for any transducer involves measuring the acoustical pressure distribution within the transmitted acoustical field. For reasons of main taining measurement reproducibility, it is mandatory that amplitude and frequency spectrum of the pulse generator be specified and rigidly duplicated for any measurement of the sound beam generated by a specific transducer. Field pressure distribution can be measured two ways: (a) using a separate receiver lransducer to sample the field or, (b) using a specified target (small ball target) to reflect a small portion of the field back to the transducer being tcsted. In either case, the measurement is made in many small volumetric increments throughout the space occupied by the field. A special note of precaution when using a target reflector is the influence the target has on the overall measurement. There is associated with any source of radiant energy a phenomenon called directivity. This refers to the pattern of the radiated energy field and is determined by the source size and shape and energy wavelength in the surrounding medium. This is true for either a 


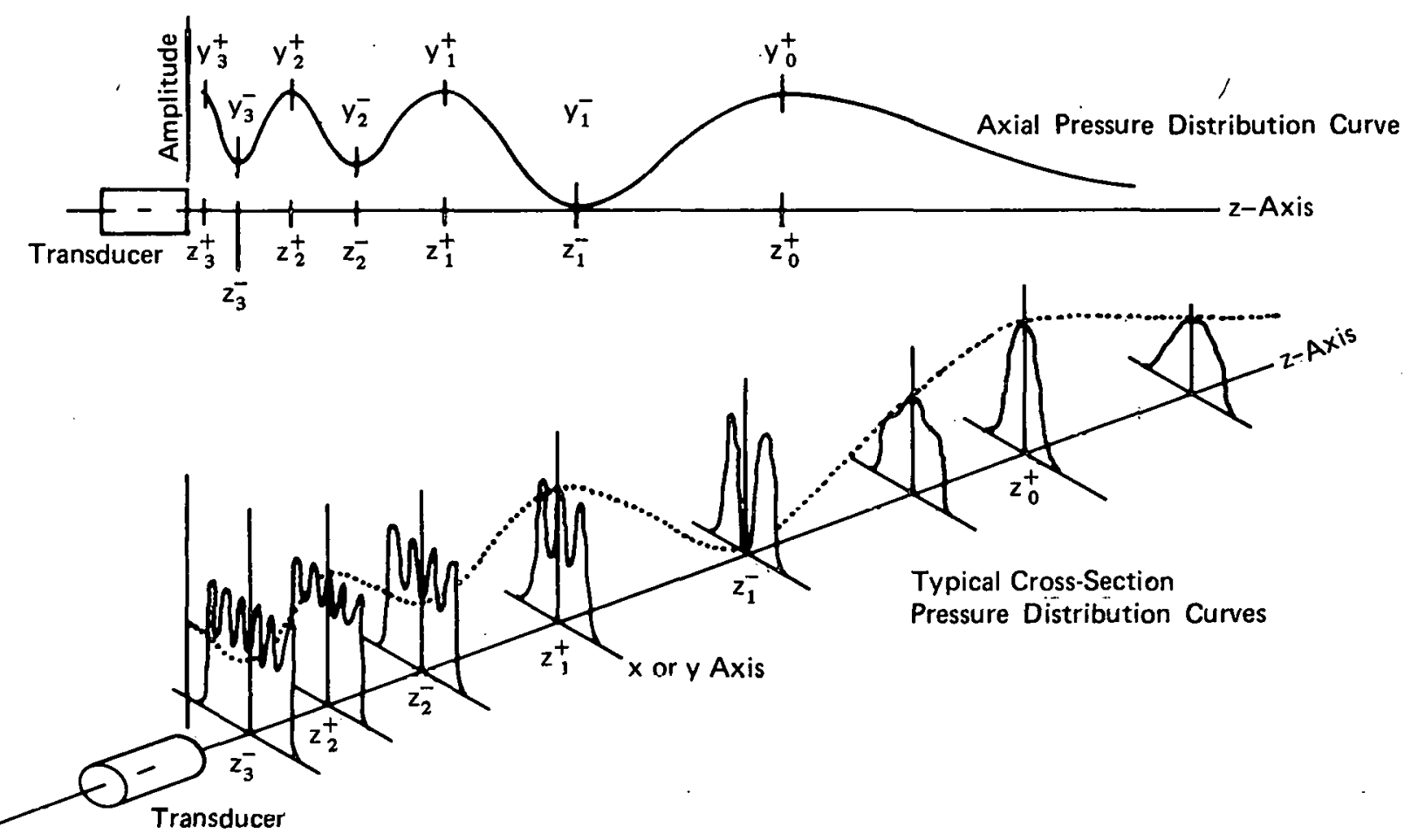

FIGURE 2. Sound Beam Profile

piezoelectric element or a reflector. The importance of this phenomenon regarding the target method measurement is the influence of the target's directivity on the field pressure amplitude. Unless the compensation is made for target influence, the sound beam profile will include this influence and will not be truly representative of the transducer character.

Since the sound beam profile is a field distributed through a volume, each field point measurement requires four data points, three position points $(\mathrm{x}, \mathrm{y}$, and $\mathrm{z})$, and the field pressure amplitude. Figure 2 shows the typical sound beam profile with the characteristic landmarks identified.

Recommended Procedure: The simplest and inherently most accurate means of measuring field pressure is with a very small, separate receiver transducer. This procedure is recommended for both comprehensive and spot check measurement of transducer fields.
The receiver transducer probe recommended for this method is a 0.010 -inch diameter broadband element mounted in a needle-like housing. The housing is designed specifically to minimize the energy reflected directly back to the transducer under test.

Mechanical fixturing for making this measurement is shown in Figure 3. The ultrasonic wave pressure is determined by the amplitude of the sample (receiver probe) signal amplitude. For production checks to ensure suitability for continued service. a standard ultrasonic flaw detection instrument can be used. It is necessary to spot check two distinctive landmarks prior to putting the transducer into service and to always use the same instrument settings for all subsequent checks.

To make the measurements for generating a sound beam profile, the transducer is placed in a fixture as shown in Figure 3 and adjusted so the axis of the sound beam and the " $\mathrm{z}$ " axis of motion are parallel. The receiver probe is placed on the tank floor with its tip directed toward the 


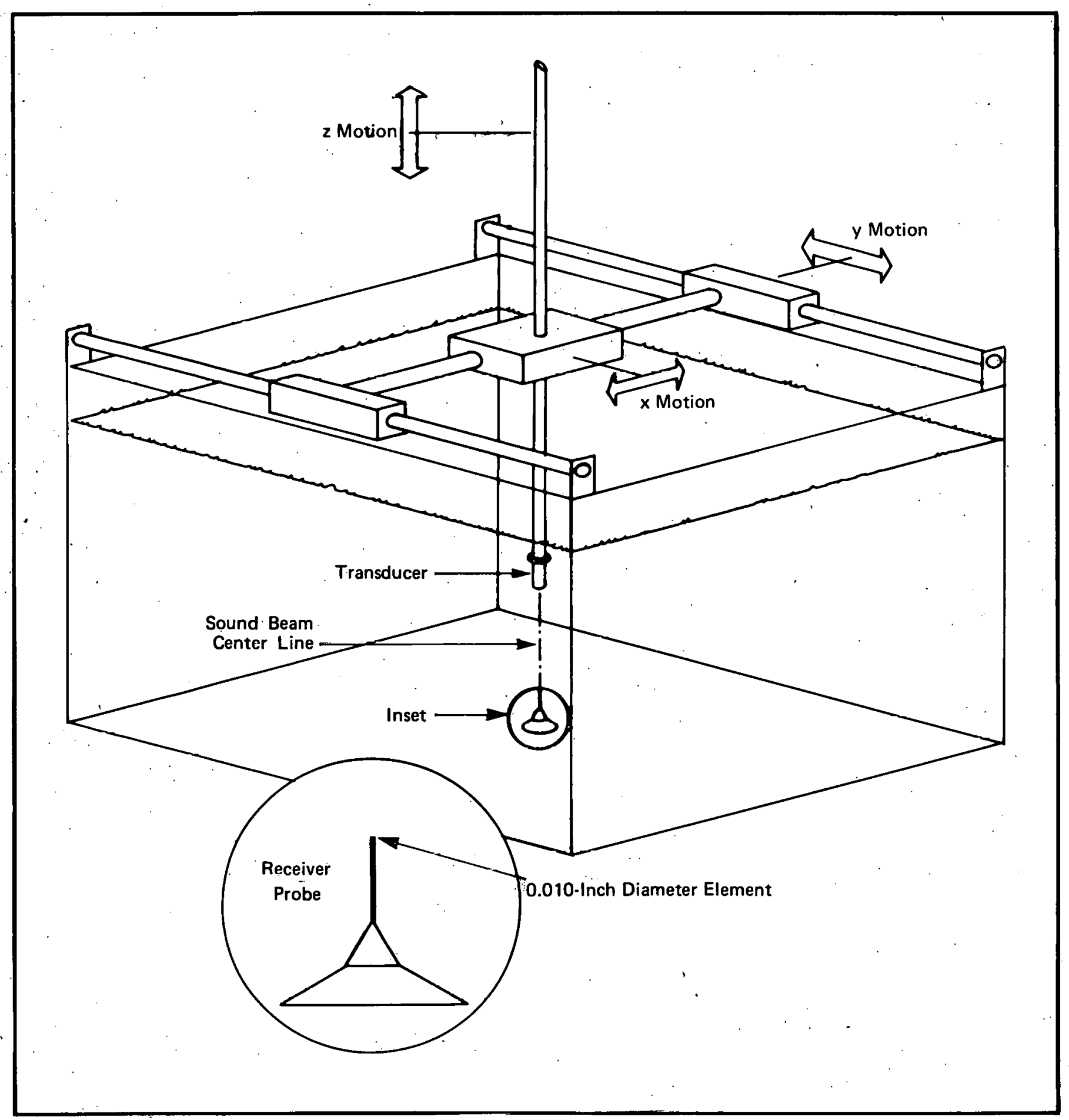

FIGURE 3. Mechanical Fixture for Making Sound Beam Profile Data Measurements 


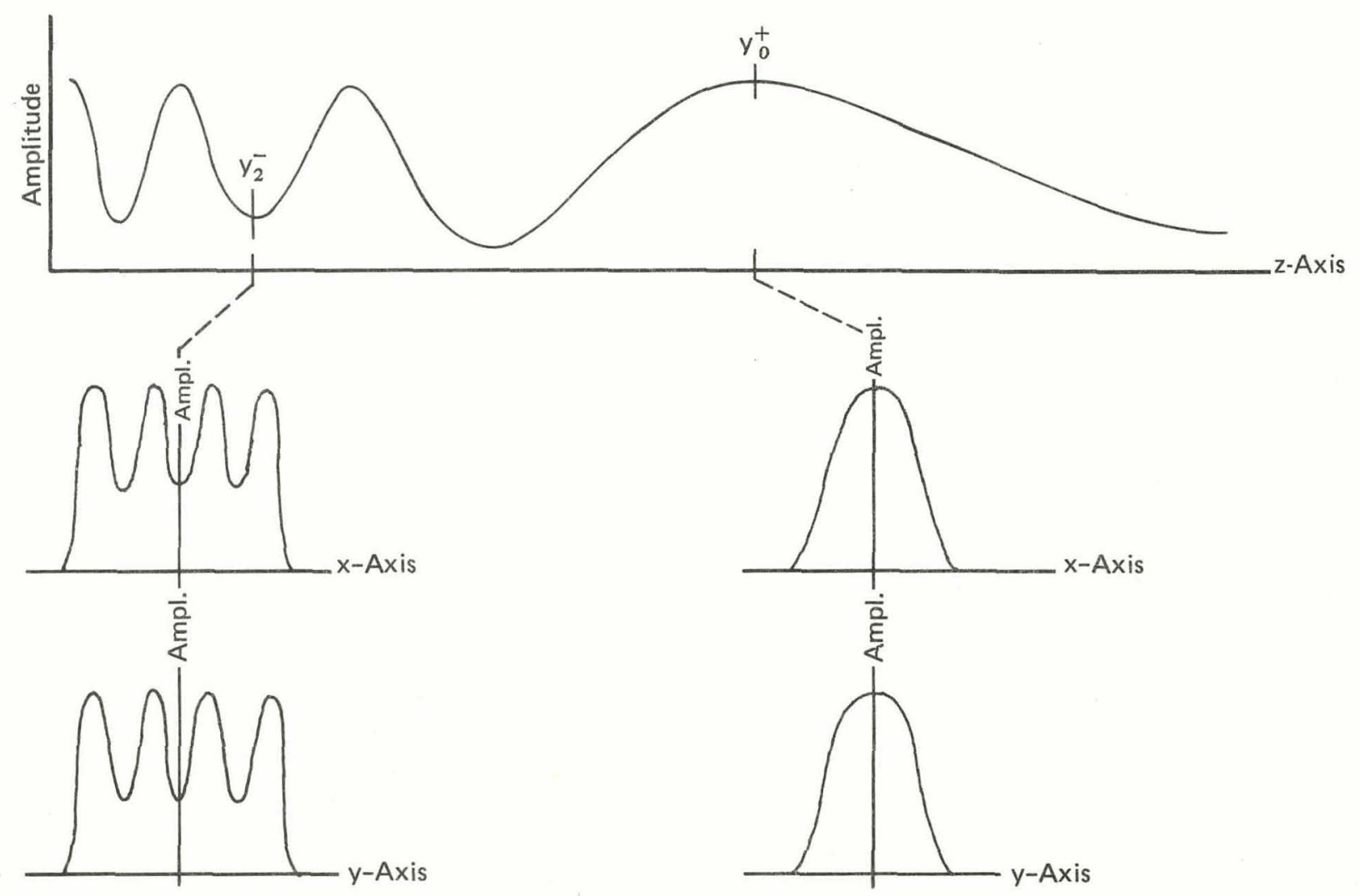

FIGURE 4. Abbreviated Sound Beam Profile Measurement at Characteristic Landmarks $y_{0}^{\dagger}$ and $y_{2}$

transducer under test. Position the transducer so the sound beam axis is coincident with the receiver probe axis and record the receiver amplitude. Vary the " $\mathrm{z}$ " position through a sufficient range to include $y_{3}^{-}$and beyond $y_{0}^{+}$, recording the receiver probe signal for each " $\mathrm{z}$ " position. Use these data to plot the axial pressure distribution curve shown in Figure 2. This plot provides " $\mathrm{z}$ " position data from which the transverse distribution data points can be measured, (the " $x$ " vs receiver amplitude and " $y$ " vs receiver amplitude). Plotting the transverse pressure distribution provides information relative to both beam diameter and beam symmetry.

Common practice in making profiling measurements is to make a quick axial pressure survey for the point of highest amplitude, then adjust the instrument gain to give an $80 \%$ signal height for the maximum receiver amplitude. Experimental data indicate that a minimum of seven cycles are required in the radio frequency signal package for the sound beam profile to agree with its theoretical values, which are based on continuous wave calculations. While seven cycles are not possible with all transducers, it is good practice to always use the least amount of instrument damping possible.

Production check of transducers can be made with an abbreviated test using only two key landmarks in the profile. For example, the $y_{0}^{+}$and $y_{2}^{-}$points for most transducers are sufficient data to determine degradation. A spot check of these two points will indicate if a transducer has changed (see Figure 4).

\section{Spectral Response}

Concept of Measurement: Spectral response of a transducer is measured by sampling the acoustical field for its frequency and energy content. The 


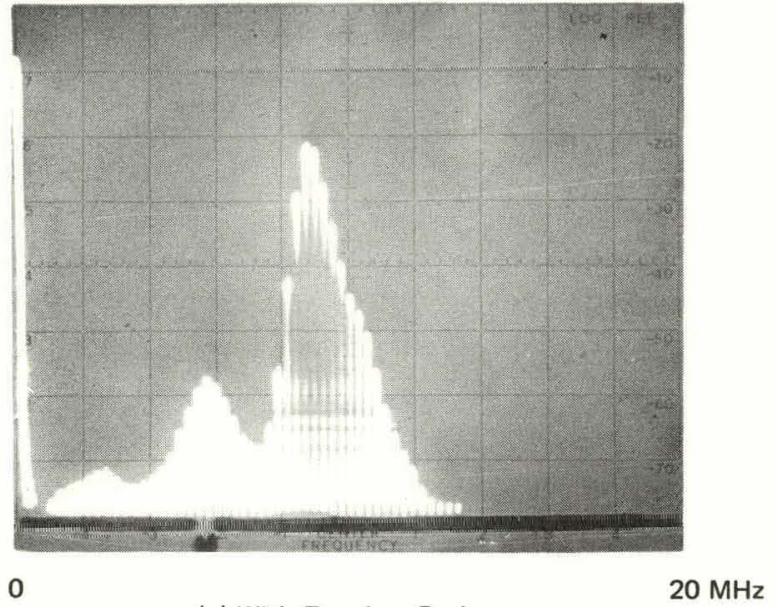

(a) With Receiver Probe

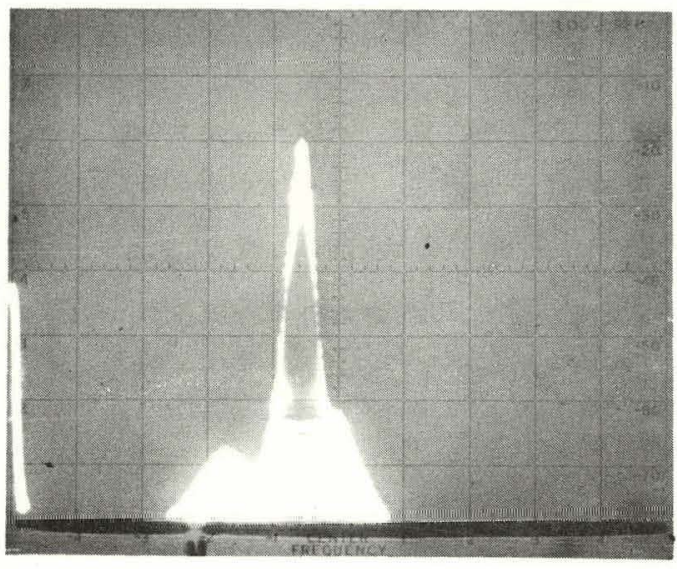

(b) With Target Reflector
$20 \mathrm{MHz}$

FIGURES 5(a) and (b). Comparison of Spectral Response Measured With Separate Receiver Probe and With Target Reflector

principle means of measurement is a spectrum analyzer that measures the energy (power) level in small increments of frequency over a broad frequency range. In this measurement, it is particularly critical that all parameters be rigidly documented and controlled.

Spectral response can be measured using either of two techniques, (a) with a separate receiver probe (as in profiling) or, (b) with a large mirror-like reflector. Either technique requires special precautions to maintain test validity.

Measurement with a receiver probe requires that all instrumentation used to receive and process the signal has sufficient band pass to encompass the total signal spectrum. This includes the band pass of the receiver probe.

Measurement with the reflector requires the same instrument specifications for band pass but includes an additional instrument called a stepless gate. This stepless gate must isolate the reflected signal without injecting any frequency content of its own. The mirror-like reflector must be much larger in cross section than the sound beam and have a surface finish at least as good as $1 / 8$ wavelength at the highest frequency. A note of caution for the mirror reflector measurement concerns the fact that acoustical energy is subjected to double influence by the transducer when pulse-echo operation is used. The transducer first transmits the sound beam and then processes the reflected sound beam. Thus, information gathered with one technique is not a duplicate of data gathered by the other (see Figure 5).

Spectrum measurement is particularly subject to influence by the transducer/pulser interaction. While the ideal solution to this problem would be an infinitely stiff pulser, the practical solution is to guarantee the pulser influence is always the same from one measurement to the next. At present, this is accomplished by documentation and rigid adherence to initial conditions in subsequent measurements. An effort is underway to develop a more ideal pulser for this work.

Recommended Procedure: This aspect of transducer characterization is not recommended for production check of transducer condition unless specifically required.

The recommended procedure is to use the same set-up and fixturing used for sound beam profiling with the receiver probe. The transducer is positioned so the receiver probe is located at $y_{0}^{+}$. The receiver 


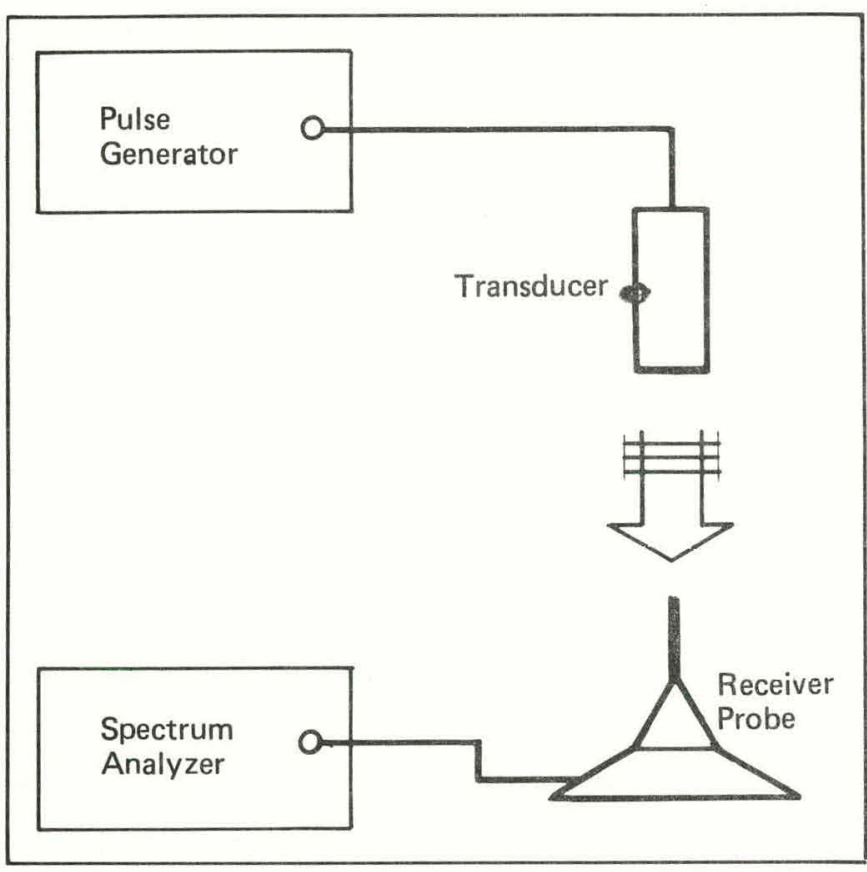

FIGURE 6. Test Set-Up for Measuring the Spectrum of Transmitted Wave

output is put into a spectrum analyzer or any device capable of making a Fourier Transform of the received signal. See Figure 6 for recommended test set-up.

The precautions previously mentioned for pulser/ transducer interaction are reemphasized because of their critical influence on this test.

\section{$\underline{\text { Sensitivity }}$}

Concept of Measurement: Sensitivity measurement is simple in concept. Theoretically, the power transmitted from the transducer for a given applied pulse voltage is measured, the power reflected by the target is measured, and the transducer signal voltage resulting from the reflection is measured. The sensitivity of the transducer is determined from these values. While this is basically the procedure used in practice, it is complicated by the inability to easily and reliably measure the small power levels transmitted by NDE type transducers. Thus, the measurement is made of only the applied pulse voltage and the amplitude of the received signal (from a known reflector). Again, the control for reliable, reproducible measurement must be

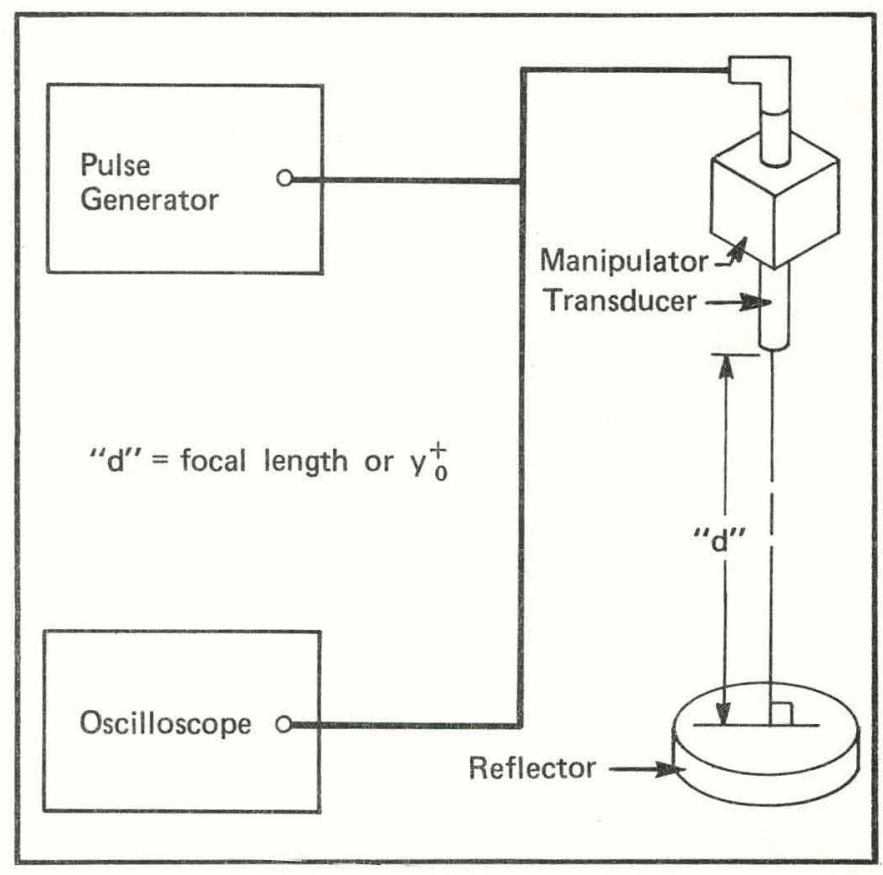

FIGURE 7. Test Set-Up to Measure Sensitivity and Damping Time

documentation and rigid adherence to initial conditions.

Recommended Procedure: This measurement is made in a pulse-echo mode of testing using a special reflector target. The target is a fused quartz cylinder $1 \mathrm{in}$. in diameter and $1 \mathrm{in}$. high. The surfaces are ground to 8 RMS finish (parallel to \pm 0.0002 inch).

Measurement is made by normalizing the transducer with the target at a water path of $1 / 2 y_{0}^{+}$for flat transducers and at the focal length for focussed transducers. The target is designed so normalization can be accomplished by monitoring both the front surface reflection and the multiple back surface reflections. Once normalcy has been achieved, an oscilloscope is used to measure the applied pulse voltage $V_{p}$ and the received signal $v_{r}$ both at the transducer. See Figures 7 and 8 for measurement set-up and method for determining voltage amplitudes. Since the actual numbers from this measurement result in a ratio much less than unity, the $v_{r} / V_{p}$ ratio is multiplied by 1000 to simplify the final value. This value is henceforth referred to as the "loop-sensitivity." 

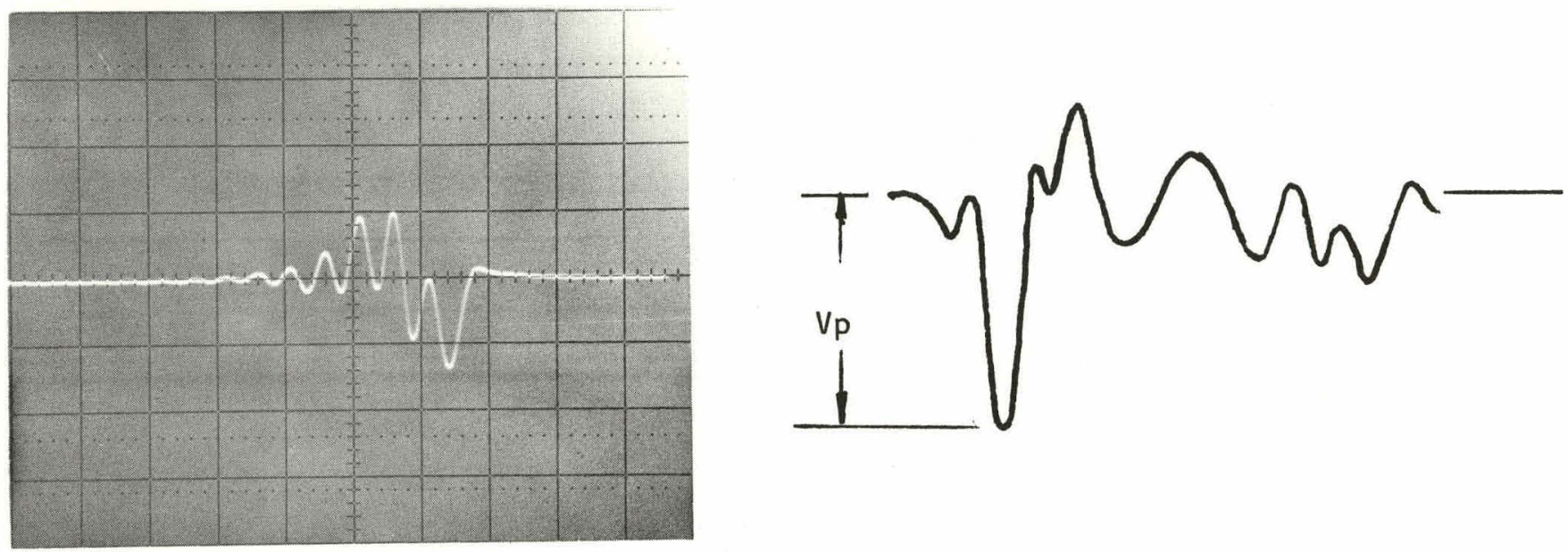

(a) Pulse signal $(50 \mathrm{~V} / \mathrm{cm})$

(b) Reflected signal $(50 \mathrm{mV} / \mathrm{cm})$
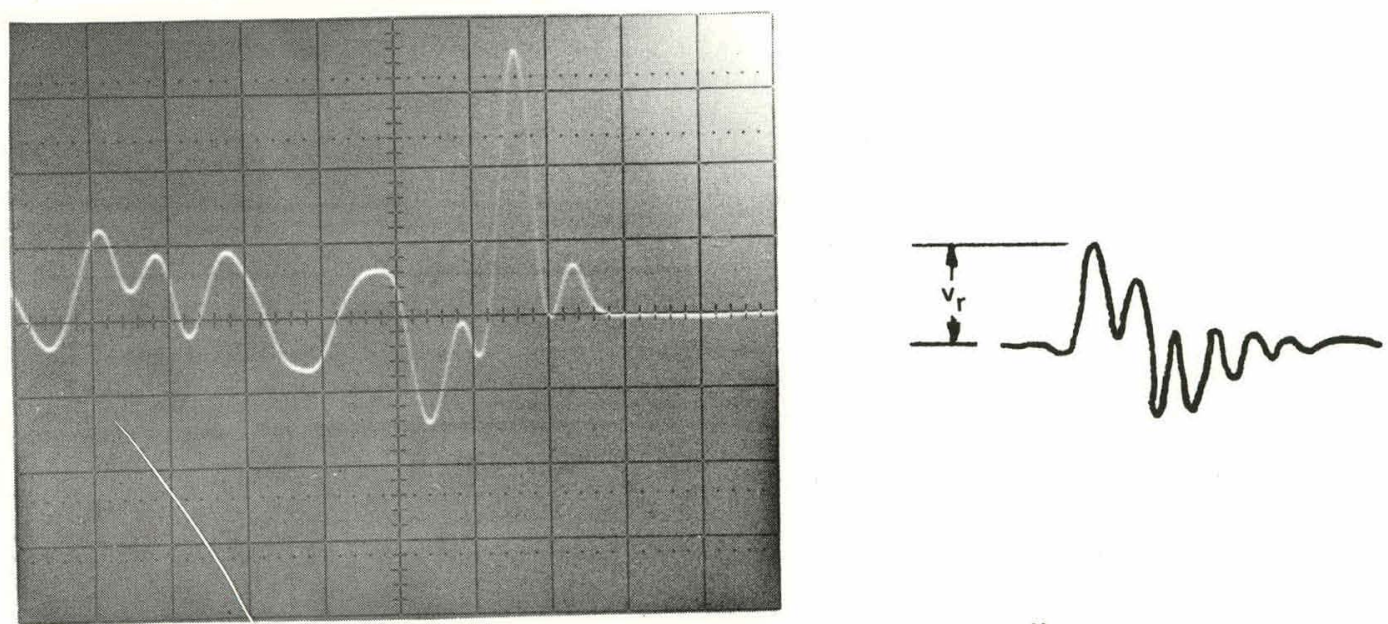

Loop Sensitivity Factor (LSF) $=\frac{v_{r}}{V_{p}} \times 1000$

FIGURES 8(a) and (b). Method for Measuring Amplitude of $\mathrm{Vp}$ and $\mathrm{v}_{\mathrm{r}}$ and Calculating LSF 

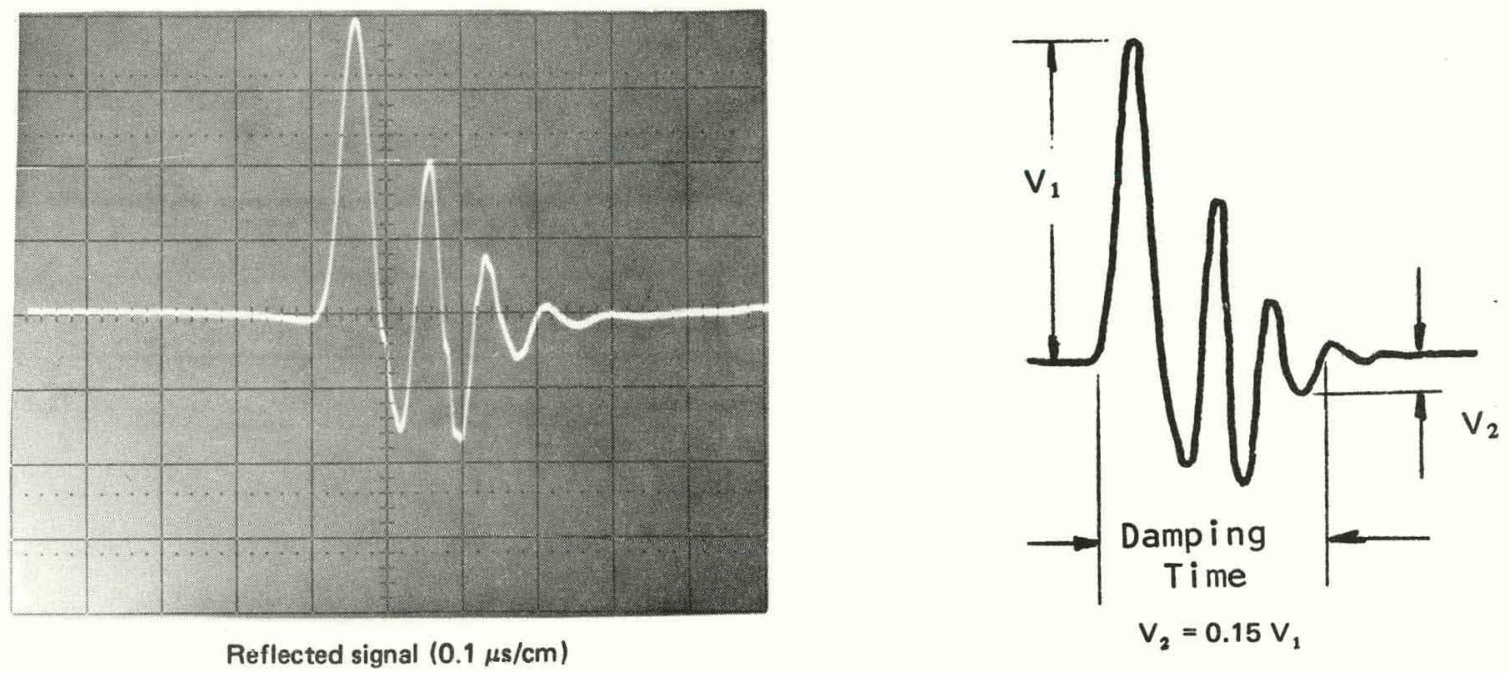

NOTE: Damping Time (DT) given in nanoseconds

FIGURE 9. Method for Measuring Damping Time

The measurement requires documentation of the initial test conditions and rigid adherence to these initial conditions for subsequent testing.

\section{Damping Time}

Concept of Measurement: The transducer parameter actually required to determine resolution capability is the time required for the transducer to reach quiescence after excitation. Therefore, "damping time" is defined as the time interval required for a reflected front surface signal to decay to $15 \%$ of its peak amplitude (half cycle peak).

Recommended Procedure: The "damping time" measurement is best made simultaneously with the sensitivity measurement. The test instrumentation, test fixture, target reflector, and set-up proce iure are identical for both measurements. Figure 7 shows test set-up for sensitivity and DT measurement. Damping time is determined as shown in Figure 9.

Precautions for making this measurement include all those given for sensitivity plus the extra requirement that the pulser's internal damping control be adjusted for minimum DT observed on the oscilloscope presentation of the front surface reflection signal. See Figure 10 for an illustration of instrument damping control influence on DT.

\section{BIBLIOGRAPHY}

B. T. Cross. "Sound Beam Directivity: A Frequency Dependent Variable." Automation Industries, Inc. Tech. Report TR70-23. 1970.

B. T. Cross. "The Spectral Aspects of Ultrasonic Flaw Detection." Automation Industries, Inc. Tech. Report TR72-48. 1972.

M. D. Fox and J. F. Uonnelly. "Simplified Method for Determining Piezoelectric Constants for Thickness Mode Transducers." J. Acoust. Soc. Am. 64(5). November 1978.

T. F. Heuter and R. H. Bolt. Sonics. John Wiley and Sons, New York. 1955.

"IRE Standards on Piezoelectric Crystals: Determination of Elastic, Piezoelectric, and Dielectric Constants - The Electromechanical Coupling Factor, 1958." Proceedings of IRE. pp. 764-778. April 1958.

"IRE Standards on Piezoelectric Crystals: Measurement of Piezoelectric Ceramics, 1961." Proceedings of IRE. pp. 1161-1169. July 1961.

"IRE Standards on Piezoelectric Crystals - The Piezoelectric Vibrator: Definitions and Methods 


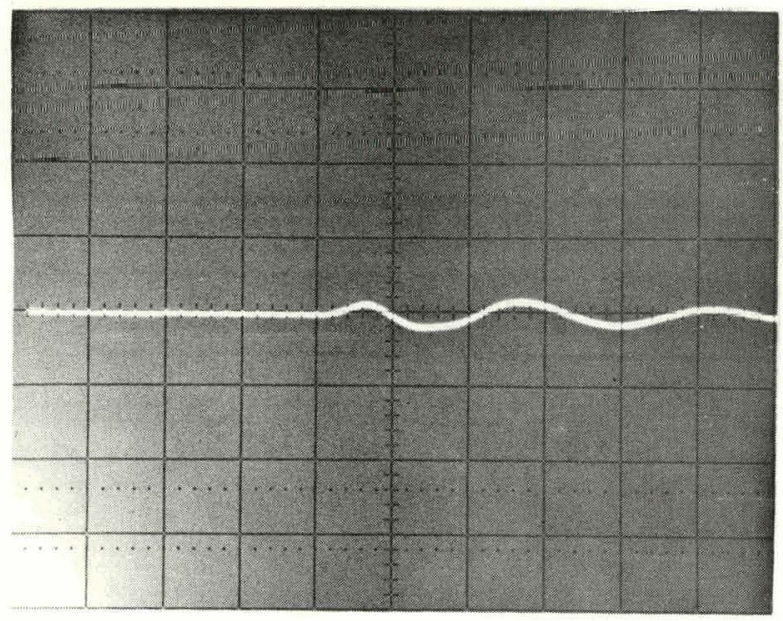

(a) Over-Damped

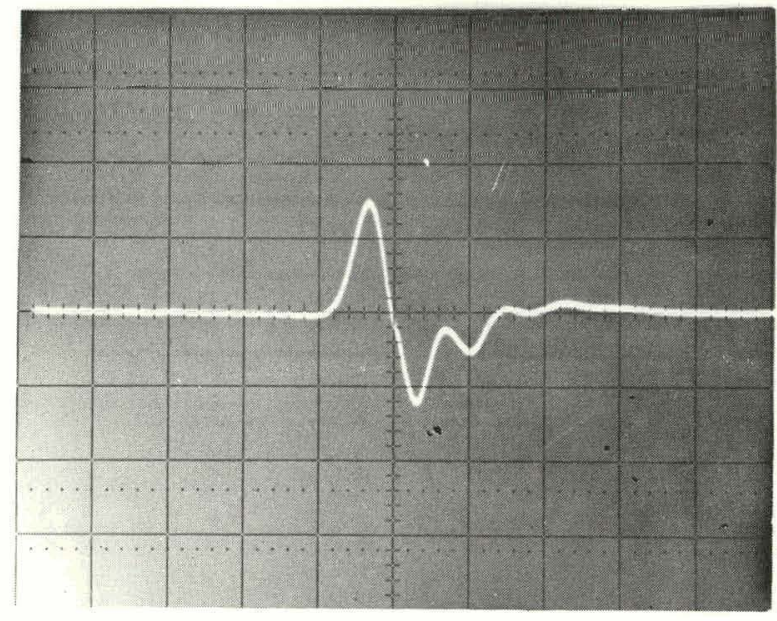

(b) Properiy-Uamped

(c) Under-Damped

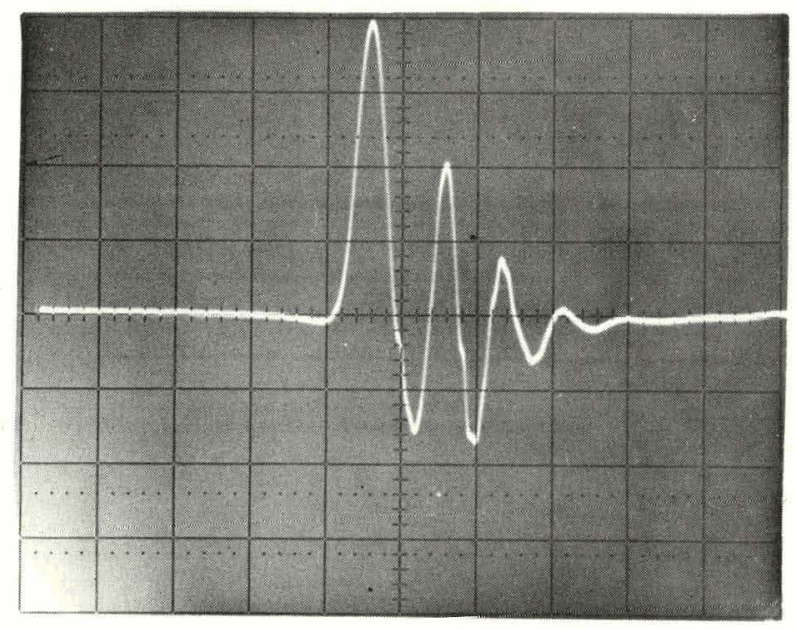

FIGURES 10(a), (b), and (c). Proper Adjustment of Instrument

Damping Control to Achieve Minimum Effective Damping

of Measurement, 1957." Proceedings of IRE. pp. 353-358. March 1957.

"IRE Standards on Piezoelectric Crystals, 1949." Proceedings of IRE. pp. 1378-1394. December 1949.

J. Krautkramer and H. Krautkramer. Ultrasonic Testing of Materials. Springer-Verlag. New York. 1969.

R. W. Martin and R. A. Sigelmann. "Force and Electrical Thevenin Equivalent Circuits and Simulations for Thickness Mode Piezoelectric Transducers." J. Acoust. Soc. Am., Vol. 58, No. 2. August 1975.
W. P. Mason and H. Jaffe. "Methods for Measuring Piezoelectric, Elastic, and Dielectric Coefficients of Crystals and Ceramics." Proceedings of IRE. pp. 921-930. June 1954.

O. E. Mattiat. Ultrasonic Transducer Materials. Plenum Press. New York - London. 1971.

J. T. McElroy. "Identification and Measurement of Ultrasonic Search Unit Characteristics." Automation, Inc. Tech. Report TR66-5. 1966.

G. J. Posakony. "Engineering Aspects of Ultrasonic Transducer Design." Ultrasonics Symposium Proceedings. IEEE Cat. No. CH0994-4SU. 1975. 